\title{
Discharge $\beta$-blocker use and race after coronary artery bypass grafting
}

\section{Wesley T. O'Neal ${ }^{1 *}$, Jimmy T. Efird ${ }^{2,3}$, Stephen W. Davies ${ }^{4}$, Jason B. O'Neal ${ }^{5}$, William F Griffin ${ }^{2}$, T. Bruce Ferguson ${ }^{2}$, W. Randolph Chitwood ${ }^{2}$ and Alan P. Kypson ${ }^{2}$}

\author{
' Department of Internal Medicine, Wake Forest School of Medicine, Winston-Salem, NC, USA \\ 2 East Carolina Heart Institute, Department of Cardiovascular Sciences, Brody School of Medicine, East Carolina University, Greenville, NC, USA \\ ${ }^{3}$ Center for Health Disparities, Brody School of Medicine, East Carolina University, Greenville, NC, USA \\ ${ }^{4}$ Department of General Surgery, University of Virginia School of Medicine, Charlottesville, VA, USA \\ ${ }^{5}$ Department of Anesthesia, Critical Care, and Pain Medicine, Beth Israel Deaconess Medical Center, Harvard Medical School, Boston, MA, USA
}

Edited by:

Marinella Gracia Temprosa, The

George Washington University, USA

\section{Reviewed by:}

Michael D. Larsen, The George

Washington University, USA

Jia Liu, Pfizer Inc., USA

Cristian Ricci, Regensburg University,

Germany

*Correspondence:

Wesley T. O'Neal, Department of Internal Medicine, Wake Forest

School of Medicine, Mail Box \#2275,

Medical Center Boulevard,

Winston-Salem, NC 27157, USA

e-mail:woneal@wakehealth.edu
Introduction: The use of discharge $\beta$-blockers after cardiac surgery is associated with a long-term mortality benefit. $\beta$-Blockers have been suggested to be less effective in black cardiovascular patients compared with whites. To date, racial differences in the long-term survival of coronary artery bypass grafting (CABG) patients who receive $\beta$-blockers at discharge have not been examined.

Methods: A retrospective cohort study was conducted on patients undergoing CABG between 2002 and 2011. Long-term survival was compared in patients who were and who were not discharged with $\beta$-blockers. Hazard ratios (HR) and 95\% confidence intervals $(\mathrm{Cl})$ were computed using a Cox regression model. P-for-interaction between race and discharge $\beta$-blocker use was computed using a likelihood ratio test.

Results: A total of $853(88 \%)$ black $(n=970)$ and 3,038 $(88 \%)$ white $(n=3,460)$ patients had a history of $\beta$-blocker use at discharge $(N=4,430)$. Black patients who received $\beta$-blockers survived longer than those not receiving $\beta$-blockers and the survival advantage was comparable with white patients (black, adjusted $\mathrm{HR}=0.33,95 \% \mathrm{Cl}=0.23-0.46$; white, adjusted $\mathrm{HR}=0.48,95 \% \mathrm{Cl}=0.39-0.58 ; p$-for-interaction $=0.74)$. Among patients discharged on $\beta$ blockers, we did not observe a long-term survival advantage for white compared with black patients $(\mathrm{HR}=1.2,95 \% \mathrm{Cl}=0.95-1.5)$.

Conclusion: $\beta$-Blocker use at discharge was associated with a survival advantage among black patients after CABG and a similar association was observed in white patients.

Keywords: outcomes, CABG, epidemiology, $\beta$-blockers, cardiology

\section{INTRODUCTION}

Coronary heart disease (CHD) is the cause of 1 in 6 deaths in the United States (1). Over the next 20 years, the prevalence of cardiovascular disease, including CHD, will increase by $10 \%$ with a threefold increase in cost (2). Modifiable risk factors (e.g., smoking, diet, obesity) lead to an increased risk of CHD and reductions in CHD mortality have been observed and attributed to public health programs of smoking cessation and the implementation of cholesterol and antihypertensive medications to patients at-risk for the development of CHD (3).

An estimated 397,000 coronary artery bypass grafting (CABG) procedures are performed annually in the United States with an estimated direct and indirect cost approaching $\$ 181$ billion (4). Between 1980 and 2000, the age-adjusted death rate due to CHD fell by $48 \%$ with $50 \%$ of this decrease being attributed to secondary preventative measures in patients with known CHD, such as the optimization of medical therapies after myocardial infarction (MI) and revascularization procedures, including $C A B G(5)$. Due to the projected increases in CHD prevalence and the known benefit of
CABG, the identification of therapies that improve outcomes in the post-surgical population is of paramount importance.

Several studies have reported that black race is associated with decreased long-term survival after CABG compared with whites $(6-10)$. In patients who have undergone CABG, those discharged on $\beta$-blockers have been reported to survive longer compared with those not discharged on $\beta$-blockers (11-13). However, racial differences in $\beta$-blocker efficacy have been reported in heart failure patients, suggesting that these therapies are less effective in black compared with white patients (14). Potentially, similar differences exist in the CABG population who are prescribed $\beta$-blockers at the time of discharge. The purpose of this study was to examine the association of discharge $\beta$-blockers on long-term survival among black CABG patients and to compare the magnitude of this association with white patients.

\section{MATERIALS AND METHODS}

This analysis and a waiver of consent were approved by the Institutional Review Board at the Brody School of Medicine, East 
Carolina University. Details of the study database and methodology have been previously described and are briefly summarized below (15-17).

\section{STUDY DESIGN}

This was a retrospective cohort study of patients undergoing firsttime, isolated CABG at the East Carolina Heart Institute between July 2002 and May 2011. Demographic data, comorbid conditions, coronary artery disease (CAD) severity, and surgical data were collected at the time of surgery. Patients who were and were not discharged on $\beta$-blockers were compared. Only black and white patients were included to minimize the potential for residual confounding ( $\sim 1 \%$ other races). Racial identity was self-reported. Emergent cases were considered a different population due to clinical instability and were excluded in our analysis $(n=98)$.

\section{DEFINITIONS}

A history of $\beta$-blocker use at discharge was the exposure variable of interest. Mortality was defined as any cause of death postoperatively. CAD was defined as at least $50 \%$ stenosis and confirmed by angiography before surgery.

\section{SETTING}

The East Carolina Heart Institute is a population-based tertiary referral heart hospital located in the center of eastern North Carolina, a rural region with a large black population (18). The institute is the largest stand-alone hospital devoted to cardiovascular care in the state of North Carolina, with an emphasis on reducing the unequal burden of cardiovascular disease in this region. The center provides care to patients that predominantly live and remain within a 150-mile radius of the medical center.

\section{DATA COLLECTION AND FOLLOW-UP}

The primary sources of data were the Society of Thoracic Surgeons Adult Cardiac Surgery Database linked with the electronic medical record at the Brody School of Medicine. The National Death Index was used to obtain death dates for patients lost to follow-up and also used to validate death information captured in our electronic medical record. Linkage with the National Death Index was based on a multiple criteria, deterministic matching algorithm, which included a patient's social security number (19). In our database, $<5 \%$ of validated deaths failed to correctly match with the National Death Index. Beginning in 2012, the use of social security numbers as a patient identifier was proscribed within our university system in compliance with $\$ 205(r)$ of the Social Security Act (20). Information on $\beta$-blocker use at discharge was not collected in our database prior to 2002.

\section{STATISTICAL ANALYSIS}

Categorical variables were reported as frequency and percentage while continuous variables were reported as mean \pm standard deviation, median, and range. Follow-up time was measured from the date of surgery to the date of death or censoring. Survival probabilities were computed using the Kaplan-Meier product-limit method and stratified by $\beta$-blocker status. The log-rank test was used to compare survival between patients with and without discharge $\beta$-blockers. Cox proportional hazard regression models were used to compute hazard ratios (HR) and $95 \%$ confidence intervals (CI) for long-term mortality. The main model was adjusted for variables that have been previously reported to be associated with cardiovascular-related mortality and included the following covariates: age, sex, race, hypertension, CAD severity, heart failure, and prior stroke. The post hoc addition of other variables into the model was performed in a pairwise fashion. $P$-for-interaction between race and discharge $\beta$-blocker use was computed using a likelihood ratio test. The test statistic of Grambsch and Therneau was used to check the proportional hazards assumption (21). Temporality during the study period was assessed by stratifying the analysis by two time periods (e.g., 2002-2006, 2007-2011). There were no missing values for the variables used in this analysis. Statistical significance for categorical variables was tested using Fisher's exact test and the Deuchler-Wilcoxon procedure for continuous variables. Statistical significance was defined as $p<0.05$. SAS Version 9.3 (Cary, NC, USA) was used for all analyses.

\section{RESULTS}

A total of $853(88 \%)$ black $(n=970)$ and $3,038(88 \%)$ white $(n=3,460)$ patients had a history of $\beta$-blocker use at discharge $(N=4,430)$. Patient characteristics are described in Table 1. Preoperative medications and postoperative complications are shown in Tables 2 and 3, respectively. The median follow-up for study participants was 4.3 years.

Five-year survival for black patients with and without discharge $\beta$-blockers was $86 \%$ and $59 \%$, respectively $(p<0.0001)$ (Figure 1). In whites, 5 -year survival for patients discharged on $\beta$-blockers was $87 \%$ compared with $70 \%$ for patients without discharge $\beta$-blockers $(p<0.0001)$ (Figure 2).

CABG patients receiving $\beta$-blockers at discharge survived significantly longer than those not receiving $\beta$-blockers (blacks: unadjusted $\mathrm{HR}=0.31,95 \% \mathrm{CI}=0.22-0.43$, adjusted $\mathrm{HR}=0.33,95 \% \mathrm{CI}=0.23-0.46$; whites: unadjusted $\mathrm{HR}=0.40$, $95 \% \mathrm{CI}=0.33-0.48$; adjusted $\mathrm{HR}=0.48,95 \% \mathrm{CI}=0.39-0.58 ; p$ for-interaction $=0.74$ ). Among patients discharged on $\beta$-blockers, we did not observe a long-term survival advantage for white compared with black patients $(\mathrm{HR}=1.2,95 \% \mathrm{CI}=0.95-1.5)$. The main result was not substantively altered $( \pm 10 \%$ change in effect size) with the pairwise addition of other variables listed in Table 1 or preoperative $\beta$-blockers.

\section{DISCUSSION}

A survival benefit was observed among black CABG patients who received discharge $\beta$-blockers and the magnitude of this association was comparable with white patients. Recent studies have focused on the impact of preoperative $\beta$-blockers and their influence on short-term mortality $(22,23)$. Only a few studies have looked at the impact of these medications at discharge on long-term survival after CABG (11-13).

An investigation of 3,102 patients discharged on $\beta$-blockers after cardiac surgery reported that patients using these medications were more likely to be alive 6 years after surgery compared with those not discharged on $\beta$-blockers (adjusted HR $=0.65,95 \%$ $\mathrm{CI}=0.49-0.87)(12)$. While the majority of patients included in this study were isolated CABG, HRs were not provided by type of 
Table 1 | Patient characteristics

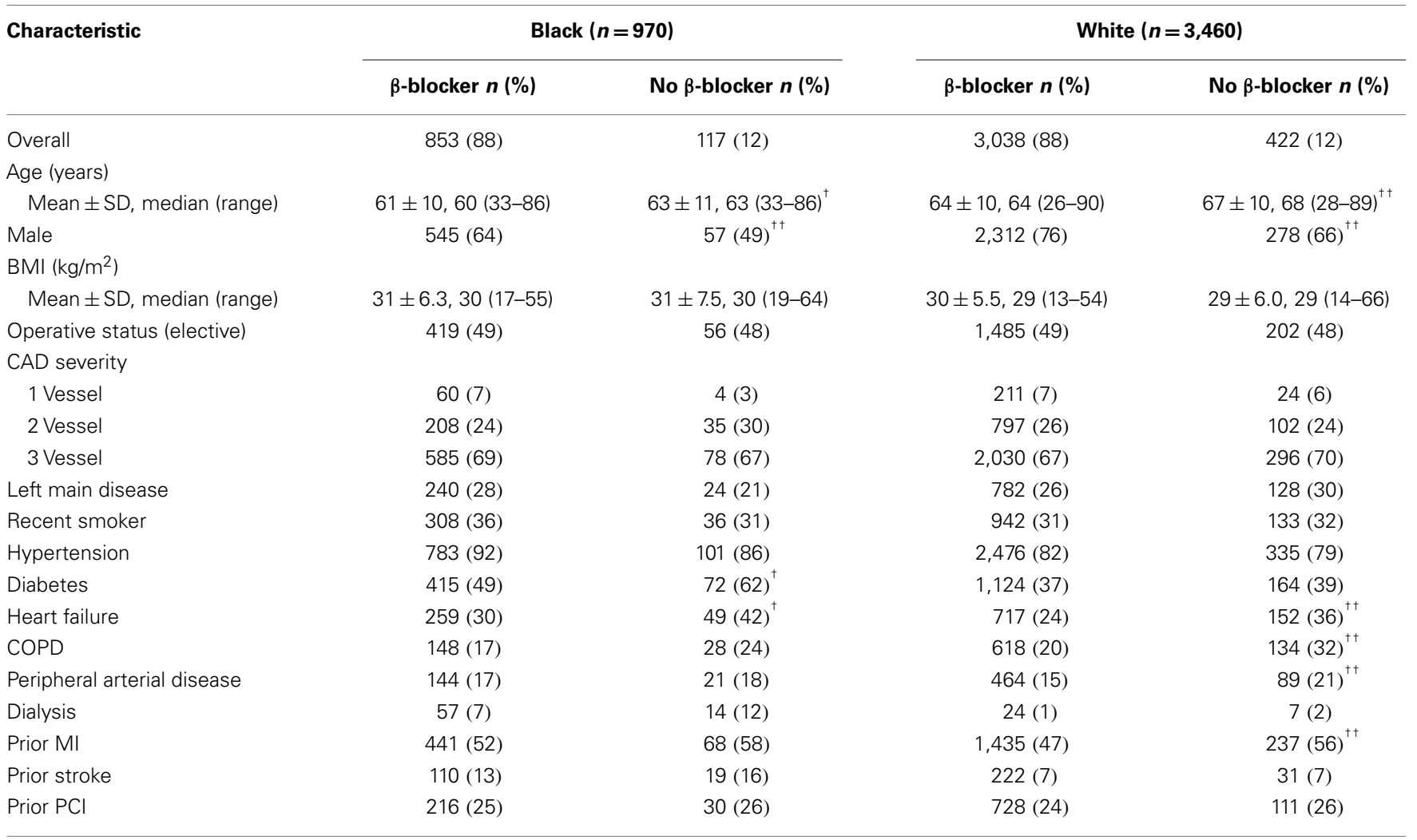

\section{${ }^{+} p<0.05$}

${ }^{t+} p<0.01$.

Statistical significance for categorical variables was tested using Fisher's exact test and the Deuchler-Wilcoxon procedure for continuous variables. $B M I$, body mass index; CAD, coronary artery disease; COPD, chronic obstructive pulmonary disease; MI, myocardial infarction; PCl, percutaneous coronary intervention; $S D$, standard deviation.

Table 2 | Preoperative medications.

\begin{tabular}{|c|c|c|c|c|}
\hline \multirow[t]{2}{*}{ Medication } & \multicolumn{2}{|c|}{ Black $(n=970)$} & \multicolumn{2}{|c|}{ White $(n=3,460)$} \\
\hline & $\beta$-blocker $n(\%)$ & No $\beta$-blocker $n$ (\%) & $\beta$-blocker $n(\%)$ & No $\beta$-blocker $n(\%)$ \\
\hline Aspirin & 665 (78) & $83(71)$ & $2,472(81)$ & $318(75)^{\dagger \dagger}$ \\
\hline Lipid-lowering agents & $634(74)$ & $79(68)$ & $2,236(74)$ & $275(65)^{\dagger+}$ \\
\hline Anticoagulants & $309(36)$ & $48(41)$ & $1,120(37)$ & $163(39)$ \\
\hline Calcium channel blockers & $213(25)$ & $36(31)$ & 536 (18) & $90(21)$ \\
\hline Diuretics & $230(27)$ & $36(31)$ & $582(19)$ & $126(30)^{\dagger \dagger}$ \\
\hline ACE inhibitors/ARBs & 469 (55) & $54(46)$ & $1,309(43)$ & $189(45)$ \\
\hline Digitalis & $23(3)$ & $13(11)^{\dagger \dagger}$ & $96(3)$ & $27(6)^{\dagger \dagger}$ \\
\hline Nitrates & $89(10)$ & $19(16)$ & 367 (12) & $54(13)$ \\
\hline Inotropic agents & $7(1)$ & $4(3)^{+}$ & $24(1)$ & $10(2)^{t+}$ \\
\hline
\end{tabular}

$$
\begin{aligned}
& { }^{\dagger} p<0.05 . \\
& { }^{\dagger+} p<0.01 .
\end{aligned}
$$

Statistical significance for categorical variables was tested using Fisher's exact test and the Deuchler-Wilcoxon procedure for continuous variables.

$A C E$, angiotensin converting enzyme; $A R B$, angiotensin receptor blocker. 
surgery. Additionally, racial differences were not examined in this study, possibly due to the limited diversity of surgical populations in western Canada.

$\beta$-Blockers were found to improve 1-year outcomes in patients with chronic obstructive pulmonary disease (adjusted $\mathrm{HR}=0.38$, $p=0.003$ ) (13). In contrast with the current study, racial differences were not reported and study populations were limited to patients with chronic obstructive pulmonary disease. Additionally, patients undergoing CABG in the PREVENT IV trial were surveyed for use of secondary prevention medications (e.g., antiplatelet agents, $\beta$-blockers, angiogtensin-converting enzyme inhibitors or angiotensin receptor blockers, and lipid-lowering agents) 1 year after hospital discharge and cardiac-related mortality was assessed at 2 years (11). Although not statistically significant, patients discharged with $\beta$-blockers observed a trend of improved survival than those not receiving $\beta$-blockers (adjusted $\mathrm{HR}=0.53,95 \% \mathrm{CI}=0.24-1.17)$. A survival advantage was not

Table 3 | Postoperative complications.

\begin{tabular}{|c|c|c|c|c|}
\hline \multirow[t]{2}{*}{ Complication } & \multicolumn{2}{|c|}{ Black $(n=970)$} & \multicolumn{2}{|c|}{ White $(n=3,460)$} \\
\hline & $\begin{array}{c}\beta \text {-blocker } \\
n(\%)\end{array}$ & $\begin{array}{c}\text { No } \beta \text {-blocker } \\
n(\%)\end{array}$ & $\begin{array}{c}\beta \text {-blocker } \\
n(\%)\end{array}$ & $\begin{array}{c}\text { No } \beta \text {-blocker } \\
n(\%)\end{array}$ \\
\hline Ml & $0(0)$ & $1(1)$ & $6(<1)$ & $3(1)$ \\
\hline Stroke & $15(2)$ & $8(7)^{\dagger+}$ & $18(1)$ & $25(6)^{t \dagger}$ \\
\hline ARDS & $4(<1)$ & $5(4)^{\dagger+}$ & $12(<1)$ & $31(7)^{t+}$ \\
\hline Pneumonia & $16(2)$ & $8(7)^{\dagger t}$ & $35(1)$ & $37(9)^{t+}$ \\
\hline Gl event* & $40(5)$ & $11(9)^{\dagger}$ & $58(2)$ & $40(9)^{\dagger \dagger}$ \\
\hline Renal failure & $18(2)$ & $10(9)^{t \dagger}$ & $38(1)$ & $39(9)^{t+}$ \\
\hline \multicolumn{5}{|l|}{$p<0.05$} \\
\hline \multicolumn{5}{|c|}{$\begin{array}{l}\text { Statistical significance for categorical variables was tested using Fisher's exact } \\
\text { test and the Deuchler-Wilcoxon procedure for continuous variables. } \\
\text { *Includes GI bleed, pancreatitis, cholecystitis, mesenteric ischemia, and other GI } \\
\text { events. }\end{array}$} \\
\hline
\end{tabular}

observed in post-CABG patients who were not ideal candidates for $\beta$-blockers (adjusted $\mathrm{HR}=1.19,95 \% \mathrm{CI}=0.70-2.01$ ).

Racial differences in the effectiveness of $\beta$-blockers in cardiovascular patients have been reported in the literature. A 2 -year follow-up study of heart failure patients receiving $\beta$ blockers observed that white patients benefited more than black patients (black: adjusted $\mathrm{HR}=0.67,95 \% \mathrm{CI}=0.48-0.94$; white: adjusted $\mathrm{HR}=0.40,95 \% \mathrm{CI}=0.27-0.60$ ) (14). However, we did not observe a statistically significant survival advantage for white patients receiving $\beta$-blockers compared with blacks. Known genetic polymorphisms in the $\beta$-adrenergic pathway possibly explain reported inconsistencies in the literature $(24,25)$.

\section{STRENGTHS AND LIMITATIONS}

Our study is strengthened by its large racially dichotomous sample size and long-term follow-up. Furthermore, we were able to accurately determine time of death using a combination of the National Death Index and our comprehensive electronic medical record.

Data regarding socioeconomic position, education, and income were not collected and these factors potentially influenced survival (26). Alcohol consumption also was not recorded in our dataset, but this variable has not been associated with increased morbidity and mortality after CABG (27). We did not have information on long-term $\beta$-blocker use. Adherence to medication among study participants may have changed. In general, $\beta$-blocker adherence has been shown to be relatively stable after CABG and any nonadherence to $\beta$-blockers after discharge likely would have biased results toward the null, decreasing the probability of finding an association of $\beta$-blocker use and long-term survival (28). However, a statistically significant result was observed in our study despite potential non-adherence to $\beta$-blocker therapies.

Physicians may have prescribed $\beta$-blockers to patients perceived to have better prognoses, potentially introducing selection bias into the analysis. However, the association of discharge $\beta$-blocker use and lower mortality was preserved after excluding patients who died within the first 30 days of surgery (black: adjusted $\mathrm{HR}=0.42,95 \% \mathrm{CI}=0.28-0.61$; white: adjusted $\mathrm{HR}=0.71,95 \%$ $\mathrm{CI}=0.56-0.90)$. Presumably, the accuracy of selecting patients who will survive diminishes following the postoperative period.

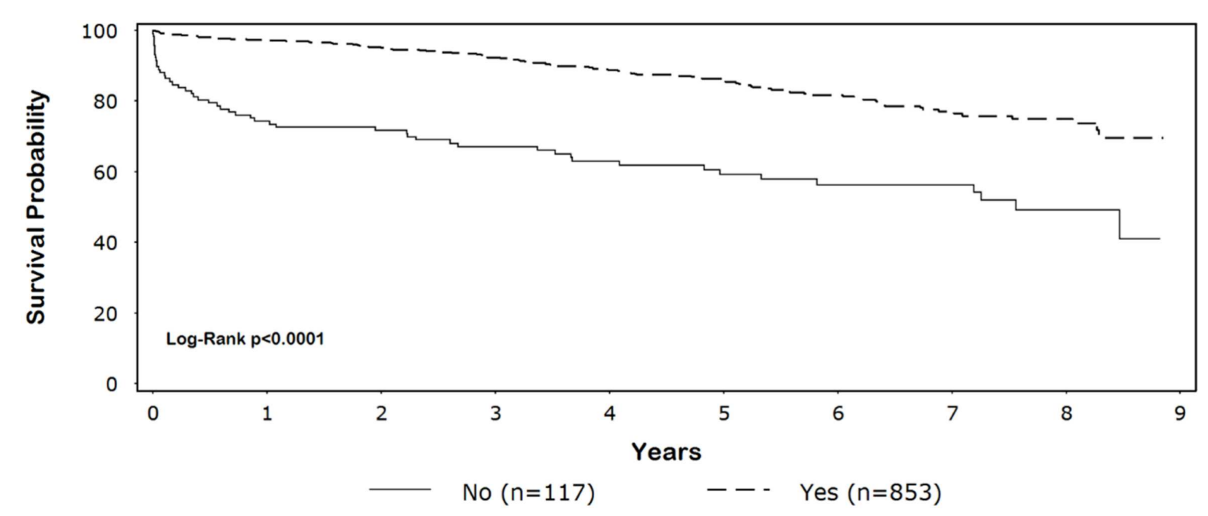

FIGURE 1 | Unadjusted Kaplan-Meier survival among black patients by $\beta$-blocker discharge status. 


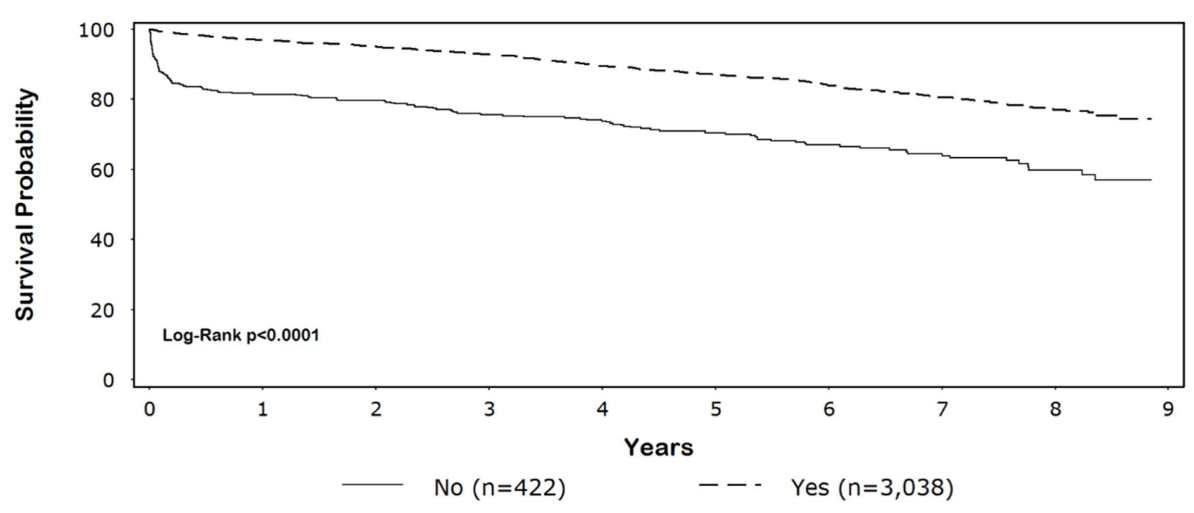

FIGURE 2 | Unadjusted Kaplan-Meier survival among white patients by $\beta$-blocker discharge status.

While $\beta$-blocker therapy is relatively contraindicated in patients with chronic obstructive pulmonary disease and may have resulted in selection bias, only a small number of these patients were not discharged on $\beta$-blockers and this percentage was similar between races. $\beta$-Blocker use also is relatively contraindicated in heart failure patients with depressed ejection fraction $(<0.35)$. However, few patients with depressed ejection fraction who did not receive $\beta$-blockers were in our dataset (black, 2.5\%; white, $2.2 \%$ ). Excluding these patients did not substantively alter our findings (black, adjusted $\mathrm{HR}=0.29,95 \% \mathrm{CI}=0.20-0.43$; white, adjusted $\mathrm{HR}=0.48,95 \% \mathrm{CI}=0.38-0.60)$.

Patients in this study were recruited over a relatively long period ( 10 years), during which practice methods and clinical care may have changed. However, adjusting for study period had little impact on our findings. Similarly, the status of several variables in our analysis may have changed over time (e.g., medications and postoperative complications). We did not adjust for these variables in a time-dependent manner due to their potential to be in the causal pathway. Cause of death is not recorded in the National Death Index and $\beta$-blocker use may have been unrelated to their mortality. Although we adjusted for known clinically relevant variables, we acknowledge that other unmeasured factors may have resulted in residual confounding. Additionally, the data reported are from a single center and may reflect a chance finding specific to our institution and region.

Multivariable Cox regression models were used to adjust for confounding because of potential "non-collapsibility bias" inherent to propensity scores based on log-linear models and the possible decrease in power due to incomplete matching (29). Additionally, a random forest algorithm (e.g., machine learning) was not used for matching. This algorithm potentially introduces misspecification bias into the propensity score model due to the "black box" nature of the algorithm that obscures the etiologic relationship between predictors and outcome $(30,31)$.

In conclusion, $\beta$-blocker use at discharge was associated with a survival advantage among black patients after CABG and the magnitude of the effect was similar to that observed among white patients. In contrast with prior studies that have reported $\beta$ blocker use is less effective in black patients, we did not observe a similar association at our institution among black CABG patients discharged on $\beta$-blockers. Additional studies are needed to better understand the underlying mechanisms of our results and to appropriately target future treatment strategies among CABG patients.

\section{ACKNOWLEDGMENTS}

The authors would like to thank the East Carolina Heart Institute for providing resources to conduct this study.

\section{REFERENCES}

1. Lloyd-Jones D, Adams RJ, Brown TM, Carnethon M, Dai S, De Simone G, et al. Executive summary: heart disease and stroke statistics - 2010 update: a report from the American Heart Association. Circulation (2010) 121:948-54. doi:10.1161/CIRCULATIONAHA.109.192666

2. Heidenreich PA, Trogdon JG, Khavjou OA, Butler J, Dracup K, Ezekowitz MD, et al. Forecasting the future of cardiovascular disease in the United States: a policy statement from the American Heart Association. Circulation (2011) 123:933-44. doi:10.1161/CIR.0b013e31820a55f5

3. Ford ES, Capewell S. Proportion of the decline in cardiovascular mortality disease due to prevention versus treatment: public health versus clinical care. Annu Rev Public Health (2011) 32:5-22. doi:10.1146/annurev-publhealth-031210101211

4. Go AS, Mozaffarian D, Roger VL, Benjamin EJ, Berry JD, Borden WB, et al. Heart disease and stroke statistics - 2013 update: a report from the American Heart Association. Circulation (2013) 127:e6-245. doi:10.1161/CIR. Ob013e31828124ad

5. Ford ES, Ajani UA, Croft JB, Critchley JA, Labarthe DR, Kottke TE, et al. Explaining the decrease in U.S. deaths from coronary disease, 1980-2000. N Engl J Med (2007) 356:2388-98. doi:10.1056/NEJMsa053935

6. Maynard C, Fisher LD, Passamani ER. Survival of black persons compared with white persons in the Coronary Artery Surgery Study (CASS). Am J Cardiol (1987) 60:513-8. doi:10.1016/0002-9149(87)90296-7

7. Gray RJ, Nessim S, Khan SS, Denton T, Matloff JM. Adverse 5-year outcome after coronary artery bypass surgery in blacks. Arch Intern Med (1996) 156:769-73. doi:10.1001/archinte.1996.00440070099011

8. Taylor HA Jr, Mickel MC, Chaitman BR, Sopko G, Cutter GR, Rogers WJ. Long-term survival of African Americans in the Coronary Artery Surgery Study (CASS). JAm Coll Cardiol (1997) 29:358-64. doi:10.1016/S0735-1097(96) 00500-1

9. Brooks MM, Jones RH, Bach RG, Chaitman BR, Kern MJ, Orszulak TA, et al. Predictors of mortality and mortality from cardiac causes in the bypass angioplasty revascularization investigation (BARI) randomized trial and registry. For the BARI investigators. Circulation (2000) 101:2682-9. doi:10.1161/01.CIR.101. 23.2682

10. Cooper WA, Thourani VH, Guyton RA, Kilgo P, Lattouf OM, Chen EP, et al. Racial disparity persists after on-pump and off-pump coronary artery bypass 
grafting. Circulation (2009) 120:S59-64. doi:10.1161/CIRCULATIONAHA.108. 843763

11. Goyal A, Alexander JH, Hafley GE, Graham SH, Mehta RH, Mack MJ, et al. Outcomes associated with the use of secondary prevention medications after coronary artery bypass graft surgery. Ann Thorac Surg (2007) 83:993-1001. doi:10.1016/j.athoracsur.2006.10.046

12. Chan AY, Mcalister FA, Norris CM, Johnstone D, Bakal JA, Ross DB, et al. Effect of beta-blocker use on outcomes after discharge in patients who underwent cardiac surgery. J Thorac Cardiovasc Surg (2010) 140:182-7. doi:10.1016/j.jtcvs. 2010.03.015

13. Angeloni E, Melina G, Roscitano A, Refice S, Capuano F, Lechiancole A, et al. Beta-blockers improve survival of patients with chronic obstructive pulmonary disease after coronary artery bypass grafting. Ann Thorac Surg (2013) 95:525-31. doi:10.1016/j.athoracsur.2012.07.080

14. Lanfear DE, Hrobowski TN, Peterson EL, Wells KE, Swadia TV, Spertus JA, et al. Association of beta-blocker exposure with outcomes in heart failure differs between African American and white patients. Circ Heart Fail (2012) 5:202-8. doi:10.1161/CIRCHEARTFAILURE.111.965780

15. Efird JT, O'Neal WT, Anderson CA, O'Neal JB, Kindell LC, Ferguson TB, et al. The effect of race and chronic obstructive pulmonary disease on long-term survival after coronary artery bypass grafting. Front Public Health (2013) 1:4. doi:10.3389/fpubh.2013.00004

16. Efird JT, O'Neal WT, O'Neal JB, Ferguson TB, Chitwood WR, Kypson AP. Effect of peripheral arterial disease and race on survival after coronary artery bypass grafting. Ann Thorac Surg (2013) 96:112-8. doi:10.1016/j.athoracsur. 2013.04.006

17. O'Neal WT, Efird JT, Anderson CA, Kindell LC, O’Neal JB, Bruce Ferguson T, et al. The impact of prior percutaneous coronary intervention on long-term survival after coronary artery bypass grafting. Heart Lung Circ (2013) 22:940-5. doi:10.1016/j.hlc.2013.04.110

18. North Carolina Facts. Available from: http://www.indexmundi.com/facts/ united-states/quick-facts/north-carolina [cited 2014 Jan 18].

19. Morales DL, Mcclellan AJ, Jacobs JP. Empowering a database with national longterm data about mortality: the use of national death registries. Cardiol Young (2008) 18:188-95. doi:10.1017/S1047951108002916

20. da Graca B, Filardo G, Nicewander D. Consequences for healthcare quality and research of the exclusion of records from the death master file. Circ Cardiovasc Qual Outcomes (2013) 6:124-8. doi:10.1161/CIRCOUTCOMES.112.968826

21. Grambsch P, Therneau T. Proportional hazards tests and diagnostics based on weighted residuals. Biometrika (1994) 81:515-26. doi:10.1093/biomet/81.3.515

22. Ferguson TB Jr, Coombs LP, Peterson ED; Society of Thoracic Surgeons National Adult Cardiac Surgery Database. Preoperative beta-blocker use and mortality and morbidity following CABG surgery in North America. JAMA (2002) 287:2221-7. doi:10.1001/jama.287.17.2221

23. Brinkman WT, Herbert MA, Prince SL, Magee MJ, Dewey TM, Smith RL, et al. Preoperative beta-blocker usage: is it really worthy of being a quality indicator? Ann Thorac Surg (2011) 92:788-95. doi:10.1016/j.athoracsur.2011.03.088
24. Cresci S, Kelly RJ, Cappola TP, Diwan A, Dries D, Kardia SL, et al. Clinical and genetic modifiers of long-term survival in heart failure. J Am Coll Cardiol (2009) 54:432-44. doi:10.1016/j.jacc.2009.05.009

25. Cresci S, Dorn GW II, Jones PG, Beitelshees AL, Li AY, Lenzini PA, et al. Adrenergic-pathway gene variants influence beta-blocker-related outcomes after acute coronary syndrome in a race-specific manner. J Am Coll Cardiol (2012) 60:898-907. doi:10.1016/j.jacc.2012.02.051

26. Koch CG, Li L, Kaplan GA, Wachterman J, Shishehbor MH, Sabik J, et al. Socioeconomic position, not race, is linked to death after cardiac surgery. Circ Cardiovasc Qual Outcomes (2010) 3:267-76. doi:10.1161/CIRCOUTCOMES.109. 880377

27. Maheshwari A, Dalton JE, Yared JP, Mascha EJ, Kurz A, Sessler DI. The association between alcohol consumption and morbidity and mortality in patients undergoing coronary artery bypass surgery. J Cardiothorac Vasc Anesth (2010) 24:580-5. doi:10.1053/j.jvca.2009.09.003

28. Okrainec K, Pilote L, Platt R, Eisenberg MJ. Use of cardiovascular medical therapy among patients undergoing coronary artery bypass graft surgery: results from the ROSETTA-CABG registry. Can J Cardiol (2006) 22:841-7. doi:10.1016/S0828-282X(06)70302-6

29. Efird JT, Lea S, Toland A, Phillips CJ. Informational odds ratio: a useful measure of epidemiologic association in environment exposure studies. Environ Health Insights (2012) 6:17-25. doi:10.4137/EHI.S9236

30. Breiman L. Random forests. Mach Learn (2001) 45:5-32. doi:10.1023/A: 1017934522171

31. Lee BK, Lessler J, Stuart EA. Improving propensity score weighting using machine learning. Stat Med (2010) 29:337-46. doi:10.1002/sim.3782

Conflict of Interest Statement: The authors declare that the research was conducted in the absence of any commercial or financial relationships that could be construed as a potential conflict of interest.

Received: 04 February 2014; paper pending published: 29 April 2014; accepted: 09 July 2014; published online: 29 July 2014.

Citation: O'Neal WT, Efird JT, Davies SW, O'Neal JB, Griffin WF, Ferguson TB, Chitwood WR and Kypson AP (2014) Discharge $\beta$-blocker use and race after coronary artery bypass grafting. Front. Public Health 2:94. doi: 10.3389/fpubh.2014.00094

This article was submitted to Epidemiology, a section of the journal Frontiers in Public Health.

Copyright () 2014 O'Neal, Efird, Davies, O’Neal, Griffin, Ferguson, Chitwood and Kypson. This is an open-access article distributed under the terms of the Creative Commons Attribution License (CC BY). The use, distribution or reproduction in other forums is permitted, provided the original author(s) or licensor are credited and that the original publication in this journal is cited, in accordance with accepted academic practice. No use, distribution or reproduction is permitted which does not comply with these terms. 